1995

\title{
Correlates of Talkaholism in New Zealand: An Intracultural Analysis of the Compulsive Communication Construct
}

\author{
Michael Z. Hackman \\ University of Colorado at Colorado Springs \\ Craig E. Johnson \\ George Fox University, cjohnson@georgefox.edu \\ Tam Barthal-Hackman \\ University of Denver
}

Follow this and additional works at: http://digitalcommons.georgefox.edu/gfsb

Part of the Business Commons

\section{Recommended Citation}

Hackman, Michael Z.; Johnson, Craig E.; and Barthal-Hackman, Tam, "Correlates of Talkaholism in New Zealand: An Intracultural Analysis of the Compulsive Communication Construct" (1995). Faculty Publications School of Business. Paper 29.

http://digitalcommons.georgefox.edu/gfsb/29 


\title{
Correlates of Talkaholism in New Zealand: An Intracultural Analysis of the Compulsive Communication Construct
}

\author{
Michael Z. Hackman \\ University of Colorado
}

\author{
Craig E. Johnson \\ George Fox College
}

Tam Barthel-Hackman

University of Denver

\begin{abstract}
This study focused on correlates of the compulsive communication construct in New Zealand. Participants were 216 New Zealand university students who completed the Talkaholic Scale to measure their tendency to be compulsive communicators. Self-reports of communication apprehension, willingness to communicate, argumentativeness, innovativeness, and self-monitoring were also completed. Results indicated a weak negative correlation with communication apprehension and weak positive correlations with argumentativeness and selfmonitoring. Differences in talkaholism between males and females were significant, but the amount of variance accounted for by biological sex was very small. This study provides further support for the distinctiveness of the compulsive communication construct and its measurement through the Talkaholic Scale.
\end{abstract}

Communication scholars have focused a great deal of attention on issues related to variability in talking behavior. Most of the research dealing with differences in talkativeness has addressed those factors believed to result in reduced levels of verbalization. Communication apprehension and avoidance, for example, have been among the most commonly studied constructs of the communication literature of the past two decades. Payne and Richmond (1984) compiled a bibliography citing nearly 1,000 articles, books, and papers directly related to communication apprehension and avoidance. By comparison, very little attention has been focused on approach tendencies of high verbalizers, particularly extremely high verbalizers (McCroskey \& Richmond, 1993). When the phenomenon of over-communication is mentioned in the literature, it is usually addressed as an atypical manifestation of high communication apprehension (McCroskey, 1984).

\footnotetext{
Michael Z. Hackman (Ph.D., University of Denver, 1986) is an associate professor in the Department of Communication at the University of Colorado-Colorado Springs, CO 80933-7150. Craig E. Johnson (Ph.D., University of Denver, 1985) is an associate professor in the Department of Communication at George Fox College. Tam Barthel-Hackman (M.A., University of Northern Colorado, 1992) is a doctoral student in the Department of Human Communication Studies at the University of Denver. The authors wish to thank Samuel Coad Dyer and Neil Harnisch of the University of Waikato, New Zealand for their assistance with data collection and Sandy Matthews of the University of Colorado-Colorado Springs for her assistance with data entry and analysis.
} 
Recently the construct of compulsive communication and a measure of this orientation, the Talkaholic Scale, were introduced into the literature (McCroskey \& Richmond, 1993; 1995). McCroskey and Richmond (1993) define compulsive communicators as "individuals who are aware of their tendencies to over-communicate in a consistent and compulsive manner" (p. 107). Such compulsive communication tendencies can be identified through scores on the Talkaholic Scale, a ten-item self-report instrument.

McCroskey and Richmond (1995) identified a number of variables related to the compulsive communication construct. They reported that compulsive communication, as measured by the Talkaholic Scale, had a low positive relationship with assertiveness, willingness to communicate, self-perceived communication competence, and neuroticism. Compulsive communication also had a low negative relationship with introversion and communication apprehension and a moderately high negative correlation with self-reports of behavioral shyness. McCroskey and Richmond (1995) argued that these low to moderate correlations support the distinctiveness of the compulsive communication construct and the Talkaholic Scale.

To further investigate the properties of compulsive communication and its measurement through the Talkaholic Scale, the present study investigated the relationship between compulsive communication and each of the following variables: communication apprehension, willingness to communicate, argumentativeness, innovativeness, and self-monitoring. Each of the variables were selected based on a presumed relationship with compulsive communication. To further extend understanding of the compulsive communication construct, data were collected outside the United States-in New Zealand.

Communication apprehension is "an individual's level of fear or anxiety associated with either real or anticipated communication with another person or persons" (McCroskey, 1977, 1984). Communication avoidance refers to the "predisposition toward approaching or avoiding the initiation of communication" (McCroskey, 1992). Recent conceptualizations of communication avoidance have focused on individual approach/avoidance tendencies labeled as willingness to communicate. Although previous research suggests compulsive communication is more than merely high communication apprehension or a low willingness to communicate, these issues merit further consideration (McCroskey \& Richmond, 1995).

Argumentativeness, the tendency to approach or avoid interpersonal argument, has been associated with increased communication competence. Infante, Wall, Leap and Danielson (1984) have indicated the tendency to argue issues may be beneficial to communicators. Infante (1982) found university students who were high argumentatives were perceived as more dynamic and experienced more success in their studies. The question remains, is there a relationship between argumentativeness and compulsive communication?

Hurt, Joseph and Cook (1977) define innovativeness as the willingness to change. This inclination to change contributes to either the adoption or rejection of new ideas. Verbalization patterns may be related to the willingness to change. Individuals with positive orientations towards interaction would most likely be more willing to engage in innovative activity than those individuals with more negative orientations towards interaction.

Self-monitoring refers to the extent to which people monitor the public appearances of self they display to others (Snyder, 1987). Those who rate high in self-monitoring are careful to control the images of self they project in social interaction. Low self-monitors, in contrast, demonstrate less concern with assessing the social climate around them. High self-monitoring has been associated with extraversion (Lippa, 1978), leadership in situations involving high verbal interaction (Garland \& Beard, 1979), and skill in oral presentation (Lippa, 1976). There may be a relationship between self-monitoring and compulsive communication. 
To date, the research on compulsive communication and its measurement (using the Talkaholic Scale) has been conducted exclusively in the United States. The present study extends the construct by investigating the correlates of compulsive communication in New Zealand. Previous research suggests New Zealanders differ from citizens of the United States in regard to talking behavior (Hackman \& Barthel-Hackman, 1993; Hackman \& Johnson, 1994). Yet to be determined is whether differences exist in relation to compulsive communication and its measurement through the Talkaholic Scale.

Finally, since there is ambiguity in the literature regarding male and female verbosity, the existence and magnitude of differences between male and female responses to the self-report measures administered in this study were investigated.

\section{METHOD}

\section{Subjects}

Participants were 216 undergraduate students (52\% males and $48 \%$ females) enrolled in introductory communication and management courses at an urban New Zealand university. Subjects closely mirrored the general ethnic composition of New Zealand with $12 \%$ of the participants listing their ethnicity as Maori; $3 \%$ as Pacific Islander; $74 \%$ as European; and 11\% as other.

\section{Measures}

The following self-report measures were used in the study:

The Talkaholic Scale: The Talkaholic Scale (McCroskey \& Richmond, 1993) includes 10 scored items and 6 filler items designed to measure compulsive communication. Previous research (McCroskey \& Richmond, 1993; 1995) suggests scores more than two standard deviations above the norm identify true talkaholics. McCroskey and Richmond (1993; 1995) reported internal reliability estimates of .92 for the Talkaholic Scale. In the present study, the internal reliability (Cronbach Alpha) of the Talkaholic Scale was .74.

Communication Apprehension: The 24-item version of the Personal Report of Communication Apprehension (PRCA-24; McCroskey, 1982) was used to measure communication apprehension. The PRCA-24 assesses communication apprehension in four contexts (public speaking, meeting, group, and dyad). The PRCA-24 has been utilized in numerous studies and has consistently shown internal reliabilities in the .91 to .96 range. In the present study, the internal reliability (Cronbach Alpha) for the total scale was .83.

Willingness to Communicate: The Willingness to Communicate (WTC) Scale (McCroskey \& Richmond, 1987) measures the predisposition toward approaching or avoiding the initiation of communication. The WTC is a 20 -item probability estimate scale made up of 12 items which comprise the scale and eight items which are fillers. The 12 items on the scale assess willingness to communicate in four contexts (public speaking, meeting, group, and dyad) and with three types of receivers (stranger, acquaintance, and friend). McCroskey (1992) reports various studies using the WTC have found estimates of internal reliability ranging from .86 to .95 with a modal estimate of .92 . In the present study, the internal reliability (Cronbach Alpha) was .87 .

The Argumentativeness Scale: The Argumentativeness Scale assesses the extent to which individuals prefer to approach or avoid communication situations in which positions on 
controversial issues are advanced and verbal attacks are made against the positions held by others (Infante \& Rancer, 1982). The Argumentativeness Scale consists of 20 items. Ten items assess the predisposition to approach argument, while the remaining items assess the predisposition to avoid argument. Overall scores are calculated by subtracting the motivation to avoid argument from the motivation to approach argument. Suzuki and Rancer (1994), in a cross-cultural investigation, report internal reliability for the approach dimension as .86 in the United States and .83 in Japan. Internal reliability for the avoidance dimension was reported as .83 in the United States and .73 in Japan. In the present study, the internal reliability (Cronbach Alpha) was .87 on the approach dimension and .83 on the avoidance dimension.

The Innovativeness Scale: The Innovativeness Scale (Hurt, Joseph \& Cook, 1977) assesses the extent to which individuals perceive themselves as innovative. The scale consists of 12 positively and eight negatively worded items. A seven-point Likert-type response format is used. Hurt et al. (1977) reported split-half internal reliability for the Innovativeness Scale at .94. Goldsmith (1986) reported a reliability coefficient of .89 for the scale. In the present study, the internal reliability (Cronbach Alpha) for the Innovativeness Scale was .83.

The Self-Monitoring Scale: The Self-Monitoring Scale (Snyder, 1987) assesses the extent to which people monitor the public images of self they display in social situations and interpersonal relationships. The Self-Monitoring Scale consists of 25 true-false, self-descriptive statements. Gangestad and Snyder (1985) reported a Kuder-Richardson 20 reliability for the Self-Monitoring Scale at .66. In the present study, the internal reliability (Cronbach Alpha) for the Self-Monitoring Scale was .64.

\section{Data Analyses}

The first phase of the data analysis involved calculation of means and standard deviations for each of the measures administered to subjects.

In the second phase of the data analysis, Pearson correlations were computed to estimate the relationships among the Talkaholic Scale scores and the scores on other measures used in the study.

The final phase of the data analysis involved a multivariate analysis of variance (MANOVA) with biological sex as the independent variable and scores on the primary measures in the study as dependent variables.

\section{RESULTS}

The means and standard deviations for each of the primary measures are reported in Table 1 .

McCroskey and Richmond (1995) suggest compulsive communication may be conceptualized as comparatively rare and highly deviant from the patterns exhibited by the average communicator. They considered those who scored more than two standard deviations above the norm on the Talkaholic Scale as true talkaholics. In their survey of 811 university students in the United States the cutoff point was a score of 40 on the Talkaholic Scale. Only $5.2 \%$ of the subjects in their study qualified for the designation of compulsive communicator. Using the same criteria for designating compulsive communicators, the mean plus two standard deviation cutoff in the present study was 39.6 (operationalized as 40 since scores are only recorded in whole numbers). The percentage of subjects scoring 40 or above on the Talkaholic Scale in this study was $4.7 \%$. 
Pearson correlations between scores on the Talkaholic Scale and the other measures in this study are reported in Table 2. All but two of the correlations were statistically significant. The correlations with willingness to communicate and innovativeness were insignificant. The only significant negative correlation $\left(r=-.16, r^{2}=.05\right)$ occurred with communication apprehension. Significant positive correlations were found with argumentativeness $\left(r=.24, r^{2}\right.$ $=.06)$ and self-monitoring $\left(r=.26, r^{2}=.07\right)$.

TABLE 1

Means and Standard Deviations for Primary Measures

\begin{tabular}{lcc}
\hline \hline Measure & Mean Score & Standard Deviation \\
\hline Talkaholic Scale & 24.4 & 7.6 \\
PRCA-24 & 69.7 & 15.0 \\
WTC & 59.4 & 15.9 \\
Argumentativeness Scale & 67.5 & 12.0 \\
Innovativeness Scale & 96.7 & 12.7 \\
Self-Monitoring Scale & 12.5 & 3.6 \\
\hline \hline
\end{tabular}

TABLE 2

Pearson Correlations with Talkaholic Scale

\begin{tabular}{lll}
\hline & $r$ & $r^{2}$ \\
\hline PRCA-24 & $-.16^{*}$ & .05 \\
WTC & .12 & .01 \\
Argumentativeness Scale & $.24^{*}$ & .06 \\
Innovativeness Scale & .05 & .00 \\
Self-Monitoring Scale & $.26^{*}$ & .07 \\
\hline${ }^{* p<.05}$ &
\end{tabular}

Table 3 reports the means, $F$-ratios, and variance accounted for by biological sex for all of the primary measures collected in this study. No significant differences were found for communication apprehension, willingness to communicate or innovativeness.

Significant differences were observed between males and females on argumentativeness $\left(F=3.74, \mathrm{df}=1,200, p<.05\right.$, eta $\left.^{2}=.02\right)$ and self-monitoring $(F=10.14, \mathrm{df}=1,200, p<.01$, $\left.\mathrm{eta}^{2}=.05\right)$. Further, a significant difference was noted on the Talkaholic Scale $(F=5.74, \mathrm{df}=$ $1,200, p<.05$, eta $^{2}=.03$ ). These differences related to biological sex were consistent with previous research in both direction and strength of the difference. 


\section{DISCUSSION}

The results of this study provide further support for the compulsive communication construct. McCroskey and Richmond (1995) note that compulsive communication is not merely extraversion, a willingness to communicate, assertiveness, or a low level of communication apprehension. Compulsive communication appears to be a distinct construct measurable through the use of the Talkaholic Scale.

TABLE 3

Means, F-Ratios, and Variance Accounted for by Biological Sex

\begin{tabular}{lccccc}
\hline \hline Measure & $\begin{array}{c}\text { Male } \\
\text { Mean }\end{array}$ & $\begin{array}{c}\text { Female } \\
\text { Mean }\end{array}$ & F-Ratio & $\begin{array}{c}\text { Significance } \\
\text { of } F\end{array}$ & $\begin{array}{c}\text { Variance } \\
\text { Accounted } \\
\text { for }\end{array}$ \\
\hline $\begin{array}{c}\text { Talkaholic } \\
\text { Scale }\end{array}$ & 22.9 & 25.9 & 5.74 & .017 & .03 \\
PRCA-24 & 68.7 & 69.3 & .33 & not sig. & -- \\
$\begin{array}{l}\text { WTC } \\
\text { Argumentativeness } \\
\text { Scale }\end{array}$ & 69.2 & 65.7 & 3.74 & .050 & .02 \\
$\begin{array}{c}\text { Innovativeness } \\
\text { Scale }\end{array}$ & 96.2 & 96.8 & .11 & not sig. &.-- \\
$\begin{array}{c}\text { Self-Monitoring } \\
\text { Scale }\end{array}$ & 13.5 & 11.8 & 10.14 & .002 & .05 \\
\hline \hline
\end{tabular}

As with previous research, the correlations of the scores on the Talkaholic Scale were moderate to weak with variables that have a strong association with approach/avoidance tendencies. In the present study, compulsive communication was associated with decreased communication apprehension, and increased argumentativeness and self-monitoring. The moderate to weak correlations were in the expected directions.

Further support for the construct and its measurement are provided by the cultural variability of the present study. Previous research using the Talkaholic Scale has been conducted exclusively in the United States. The results of this study, conducted in New Zealand, were remarkably similar to the findings reported in the United States. The cutoff point for the designation of compulsive communicator in this study was identical to the cutoff point reported in the United States by McCroskey and Richmond (1995). Further, the percentage of talkaholics among the subjects sampled in this study closely mirror the percentages found in the United States research.

Male and female mean scores on the Talkaholic Scale were almost identical to those reported by McCroskey and Richmond (1995). The results of the present study support the notion that although differences in talkaholism between males and females are significant, the amount of variance accounted for by biological sex is very small. McCroskey and Richmond (1995) found that biological sex accounted for $2 \%$ of the variation in talkaholism among their sample of United States students. The present study found that biological sex accounted for 3\% of the variation in talkaholism among the New Zealand students sampled. In both cases, females 
rated themselves higher on the Talkaholic Scale than males. Spender (1980) explains there may be different expectations for male and female speakers; while men may believe they have the right to speak, women often are expected to be silent. Talking, at any length, then, may be perceived as talkativeness in women.

The Talkaholism Scale and the compulsive communication construct are recent additions to the communication literature (McCroskey \& Richmond, 1993). The present study lends additional support to the use of the Talkaholic Scale as a valid measure of compulsive communication. Further research into the distinctiveness of compulsive communication and possible antecedent and related variables will be required to gain a deeper understanding of the relatively rare communication behavior of the compulsive communicator. Additionally, research focusing on possible differences between the self-perceived and other-perceived effectiveness of the compulsive communicator along with the perceived desirability of interacting with such individuals may provide additional clarification regarding this construct.

\section{REFERENCES}

Gangestad, S., \& Snyder, M. (1985). "To carve nature at its joints": On the existence of discrete classes in personality. Psychological Review, 92, 317-349.

Garland, J., \& Beard, J. F. (1979). Relationship between self- monitoring and leader emergence across two task situations. Journal of Applied Psychology, 64, 72-76.

Goldsmith, R. E. (1986). Convergent validity of four innovativeness scales. Educational and Psychological Measurement, 46, 81-87.

Hackman, M. Z., \& Barthel-Hackman, T. A. (1993). Communication apprehension, willingness to communicate, and sense of humor: United States and New Zealand perspectives. Communication Quarterly, 41, 282-291.

Hackman, M. Z., \& Johnson, C. E. (1994). A cross-cultural investigation of innovativeness, willingness to communicate and need for cognition. Paper presented at the Speech Communication Association annual meeting, New Orleans, LA.

Hurt, H. T., Joseph, K., \& Cook, C. D. (1977). Scales for the measurement of innovativeness. Human Communication Research, 4, 58-65.

Infante, D. A. (1982). The argumentative student in the speech communication classroom: An investigation and implications. Communication Education, 31, 141-148.

Infante, D. A., \& Rancer, A. S. (1982). A conceptualization and measure of argumentativeness. Journal of Personality Assessment, 46, 72-80.

Infante, D. A., Wall, C. H., Leap, C. J., \& Danielson, K. (1984). Verbal aggression as a function of the receiver's argumentativeness. Communication Research Reports, 1 , 33-37.

Lippa, R. (1976). Expressive control and the leakage of dispositional introversion-extraversion during role- played teaching. Journal of Personality, 44, 541-559.

Lippa, R. (1978). Expressive control, expressive consistency, and the correspondence between expressive behavior and personality. Journal of Personality, 46, 438-461.

McCroskey, J. C. (1977). Oral communication: A summary of recent theory and research. Human Communication Research, 4, 78-96.

McCroskey, J. C. (1982). An introduction to rhetorical communication, 4th ed. Englewood Cliffs, NJ: Prentice-Hall.

McCroskey, J. C. (1984). The communication apprehension perspective. In J. Daly \& J. McCroskey (Eds.), Avoiding communication: Shyness, reticence, and communication apprehension (pp. 13-38). Beverly Hills, CA: Sage. 
McCroskey, J. C. (1992). Reliability and validity of the willingness to communicate scale. Communication Quarterly, 40, 16-25.

McCroskey, J. C., \& Richmond, V. P. (1987). Willingness to communicate. In J.C. McCroskey \& J.A. Daly (Eds.), Personality and interpersonal communication (pp. 129-156). Newbury Park, CA: Sage.

McCroskey, J. C., \& Richmond, V. P. (1993). Identifying compulsive communicators: The talkaholic scale. Communication Research Reports, 10, 107-114.

McCroskey, J. C., \& Richmond, V. P. (1995). Correlates of compulsive communication: Quantitative and qualitative characteristics. Communication Quarterly, 43, 39-52.

Payne, S. K., \& Richmond, V. P. (1984). A bibliography of related research and theory. In J. Daly \& J. McCroskey (Eds.), Avoiding communication: Shyness, reticence, and communication apprehension (pp. 247-294). Beverly Hills, CA: Sage

Snyder, M. (1987). Public appearances/private realities: The psychology of self-monitoring. New York: W.H. Freeman.

Spender, D. (1980). Man made language. London: Routledge \& Kegan.

Suzuki, S., \& Rancer, A. S. (1994). Argumentativeness and verbal aggressiveness: Testing for conceptual and measurement equivalence across cultures. Communication Monographs, $61,256-279$. 